society undertakes to defray the ophthalmologist's fee of one guinea."

Though the above arrangements are good so far as they go they do not provide satisfactory ophthalmic treatment for all insured patients who require it. The "ophthalmic benefit" is not yet a "standard benefit" available to all insured persons throughout the country; only those are entitled to receive it who are nembers of approved societies having surplus funds, which agree to give the benefit, after having received the sanction of the Ministry of Health. Even then the member must have been attached to the society the whole of the time whilst the surplus has been accumulating.

It has already become apparent that some of the societies which have adopted the benefit are not administering it strictly in accordance with the intentions of the Ministry of Health. Some of the officials protest that their societies are unable to pay an ophthalmic surgeon's fee in all cases and adopt the dangerous practice of sending some of their members direct to opticians. Such societies naturally find a difficulty in deciding which cases to send to ophthalmic surgeons and which to opticians, and forms have been issued by them in which the insurance practitioner is invited to make this decision, a responsibility which, if wise, he will seldom undertake.

Obviously, the whole matter of the administration of ophthalmic benefits still requires vigilance and careful consideration. It is very desirable that the joint committee of the Council of British Ophthalmologists and the British Medical Association, which has already accomplished so much, should be resuscitated to carry on still further its useful work.

\title{
The Welfare of the Blind
}

Ophthalmology is primarily concerned with the prevention and not with the treatment of blindness. Unfortunately our efforts are not always crowned with success, hence the care of the blind becomes a subject of interest to all of us. The great war, by adding numbers of intelligent and, apart from their blindness, sound young adults to the ranks of the blind, brought about considerable improvements in the methods of educating them, not only to be self-supporting, but also to share in many enjoyments previously denied to them. Amongst the latter, Braille, as applied to literature and music, takes the first place.

The most important Braille library is that of the National Library for the Blind, with headquarters in London and a Northern branch in Manchester. The library was founded in 1882 by a 
blind lady and a friend. The few books they and their friends were able 10 produce by hand were lent out at a charge of a penny per week. At the present time the library (free to all blind readers) contains nearly 106,000 volumes at headquarters in Westminster and 15,000 in Manchester. These figures represent about 10,000 books. The catalogue includes a wide range in fiction, theology, science, sociologv, poetry, foreign literature, and music. The circulation of books to all parts of the kingdom and to the oversea Dominions is very large: in 1925-6, 137,285 volumes were sent out from headquarters, and 47,651 from Manchester.

Increased accommodation for the library is urgently needed and the Committee are, for the first time, appealing to the public for funds to complete an extension of the building now in course of erection.

Another library on a smaller scale is in process of formation by the National Institute for the Blind. The books and periodicals produced by the Institute are either given away free to individuals and libraries or sold at a reduction of two-thirds or three-quarters of the cost price. The Institute has decided to think Imperially and to extend these terms to all parts of the British Empire. The students' library is of special value. No matter how abstruse a work may be, provided it is required for the studies of a single blind student, the Braille copy is produced with all speed and loaned to that student for as long as he needs it. In this way a library of over 4,000 volumes has been built up, mainly by the devoted work of volunteers, and these books are available to every bona fide student.

Valuable though the library of the Institute may be it is one of the less important of its many activities. The provision of home-work and of convalescent homes for the blind has a very practical value. Further, an amicable arrangement has now been reached between the National Institute, the local voluntary agencies, and the local authorities concerned with the administration of the Blind Pensions Act, whereby it is hoped that the many petty jealousies which have hampered work for the blind in the past may disappear. All those interested in the beneficent work of the Institute should obtain a copy of the last, profusely illustrated, report.

Our readers may feel confident that any subscriptions they may be the means of obtaining will be put to the best use by both these institutions. 